\title{
A tale of two communities: intestinal polyparasitism among Orang Asli and Malay communities in rural Terengganu, Malaysia
}

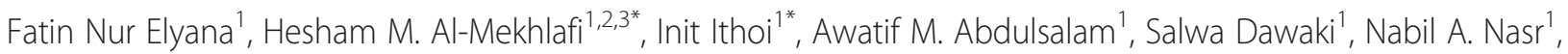
Wahib M. Atroosh', Mohamad Hafiz Abd-Basher ${ }^{1}$, Mona A. Al-Areegi ${ }^{1}$, Hany Sady ${ }^{1}$, Lahvanya R. Subramaniam', Tengku Shahrul Anuar ${ }^{4,5}$, Yee Ling Lau', Norhayati Moktar ${ }^{6}$ and Johari Surin ${ }^{1,7}$

\begin{abstract}
Background: Intestinal parasitic infections (IPIs) are still major health problems in many developing countries including Malaysia, particularly in the poor and socioeconomically deprived rural and remote communities in Peninsular Malaysia. This study was conducted to determine the prevalence of IPIs and to identify the key factors associated with intestinal polyparasitism as well as to evaluate the knowledge, attitude and practices (KAP) on IPIs among rural Orang Asli and Malay communities in Terengganu, Malaysia.

Methods: A cross-sectional study was conducted among 340 participants (165 Orang Asli and 175 Malay) aged $\leq$ 15 years from the Hulu Terengganu and Kemaman districts of Terengganu. Faecal samples were examined for the presence of intestinal parasites by using direct smear, formalin-ether sedimentation, trichrome stain, modified Ziehl Neelsen stain, in vitro cultivation in Jones' medium, Kato Katz and Harada Mori techniques. Demographic, socioeconomic, environmental and behavioural information of the participants and their KAP for IPIs were collected by using a pre-tested questionnaire.

Results: Overall, 149 (90.3\%) Orang Asli and 43 (24.6\%) Malay children were infected by at least one parasite species. The overall prevalences of intestinal polyparasitism among the Orang Asli and Malay were $68.5 \%$ (113/165) and $14.3 \%$ (25/175), respectively. Multiple logistic regression analysis showed that using unsafe water supply as a source for drinking water, the presence of domestic animals, not wearing shoes when outside, not washing vegetables before consumption, not washing hands after playing with soil, indiscriminate defecation and the low level of mother's education were the key risk factors for intestinal polyparasitism among the Orang Asli, while working mothers and the presence of domestic animals were the risk factors among the Malay children. Almost all the Malays were well aware about the IPIs while Orang Asli respondents had a poor level of related awareness.

Conclusions: This study demonstrates that IPIs are highly prevalent in rural Terengganu, Malaysia.

Community awareness about IPIs was found to be imperative in protecting Malay children from these infections. An integrated control programme for the prevention and control of IPIs is highly recommended for these communities, with a special emphasis on the Orang Asli population.
\end{abstract}

Keywords: Intestinal parasitic infections, Polyparasitism, Neglected tropical diseases, Soil-transmitted helminths, KAP, Orang Asli, Malay, Malaysia

\footnotetext{
*Correspondence: halmekhlafi@yahoo.com; init@um.edu.my

'Department of Parasitology, Faculty of Medicine, University of Malaya, 50603

Kuala Lumpur, Malaysia

Full list of author information is available at the end of the article
}

(c) 2016 The Author(s). Open Access This article is distributed under the terms of the Creative Commons Attribution 4.0 International License (http://creativecommons.org/licenses/by/4.0/), which permits unrestricted use, distribution, and reproduction in any medium, provided you give appropriate credit to the original author(s) and the source, provide a link to the Creative Commons license, and indicate if changes were made. The Creative Commons Public Domain Dedication waiver (http://creativecommons.org/publicdomain/zero/1.0/) applies to the data made available in this article, unless otherwise stated. 


\section{Background}

Intestinal parasitic infections (IPIs) are still major public health problems worldwide, particularly among children in poor and rural communities of most countries in tropical regions. It is estimated that about 2.0 billion people are infected with at least one intestinal parasite species while about 4.0 billion are at risk of infection [1, 2]. IPIs are caused by either helminths, such as Ascaris lumbricoides, Trichuris trichiura, hookworms, Strongyloides stercoralis and Taenia spp., or protozoan parasites, such as Entamoeba histolytica, Giardia duodenalis, Cryptosporidium spp., Cyclospora spp. and Blastocystis sp. [3, 4]. It is well documented that IPIs are associated with a complex web of causation that involves poverty (which is, in general, the root of these problems), inadequate sanitation, poor hygienic practices, illiteracy, ecosystem differences and overcrowding $[5,6]$.

Generally, IPIs occur silently as chronic infections and so the infected individuals are either asymptomatic or suffer from mild diseases; hence, these infections are considered as disablers rather than killers [1]. When measured in disability-adjusted life years (DALYs), the most recent global estimates revealed that over 16 million DALYs are lost to IPIs (for instance, 8.37 million by cryptosporidiosis, 4.64 million by STH infections and 2.24 million by amoebiasis) [1, 2, 7]. Moreover, numerous studies reported that IPIs (mainly soil-transmitted helminths (STH) and giardiasis) during childhood are significantly associated with protein-energy malnutrition, iron deficiency anaemia (IDA), vitamin A deficiency (VAD), intellectual retardation and educational deficits that consequently lead to poor school attendance and poor educational achievement [8-13]. Moreover, the impact of these infections increased with the number of parasite species and intensity of infections $[14,15]$. It was found that polyparasitism (the concurrent infection with multiple parasite species) is associated with higher mortality rates and may increase the sufferers' susceptibility to other infections $[15,16]$. In addition, the adverse consequences of these infections may continue into the adulthood with effects on the economic productivity and trapped the endemic populations in a cycle of poverty, underdevelopment and disease [17].

Despite the great socioeconomic and infrastructural development in Malaysia, several studies have demonstrated a high prevalence of IPIs with prominent morbidity in underprivileged communities, which is a trend that remains largely unchanged since the 1920s [18-25]. Unfortunately, data on IPIs among rural Malay population in Malaysia are not available and no study has yet addressed the status of these infections in Terengganu state, Malaysia. The present study aims to fill these gaps of information by investigating and comparing the prevalence, associated risk factors and people's knowledge, attitude and practices (KAP) towards IPIs among the Orang
Asli and the Malay populations in rural Terengganu, Malaysia. This information is important for a rationale design and implementation of effective control and prevention programmes against the IPIs among different rural communities in Malaysia.

\section{Methods}

\section{Study design and study area}

A cross-sectional, community-based study was carried out between January 2014 and August 2015 in Hulu Terengganu and Kemaman districts of Terengganu state, northeast Kuala Lumpur. There are only two Orang Asli communities in Terengganu comprised of two villages, Sungai Pergam village in Kemaman District and Sungai Berua village in Hulu Terengganu District. All villagers belong to the Senoi tribe. For the purpose of comparison, five villages were purposively selected for this study, namely Sungai Berua and Sungai Pergam villages for the Orang Asli population, and Bukit Kepah, Tapah and Felda Neram 1 villages for the Malay population; the villages of Orang Asli and Malay population are located close to each other (Fig. 1).

Terengganu state is situated in north-eastern Peninsular Malaysia and consists of eight districts. It has a population of about 1.0 million, with the Malays making up $94.7 \%$ of the population, followed by the Chinese (2.6\%), with $49 \%$ residing in rural areas [26]. The Hulu Terengganu District $\left(102.52^{\circ} \mathrm{E}, 5.01^{\circ} \mathrm{N}\right)$ is located near Kelantan and Pahang state borders, with a total area of $3874 \mathrm{~km}^{2}$ and a total population of 73,912, according to the population census 2010 [26]. Likewise, the Kemaman district $\left(103.26^{\circ} \mathrm{E}, 4.36^{\circ}\right.$ $\mathrm{N}$ ) is located at the south of Terengganu state on the east coast of Malaysia facing the South China Sea, with a total area of $2536 \mathrm{~km}^{2}$ and a total population of 166,750. Generally, both districts, Hulu Terengganu and Kemaman, boast a tropical climate, with temperatures averaging from $26{ }^{\circ} \mathrm{C}$ to $32{ }^{\circ} \mathrm{C}$ and a mean humidity of $90 \%$. Rainfall is copious with an average of $2736 \mathrm{~mm}$ per year and the vegetation is the thick rainforest type and there are few streams in the area.

\section{Study population and sample size}

The main ethnic groups in Malaysia are Malays (54.1\%), Chinese (25.4\%) and Indians (7.5\%). Indigenous groups include the Orang Asli, Kadazans, Ibans and various other groups, all accounting for $11.7 \%$ of the country's total population ( 28 million) [26]. Orang Asli (a Malay term transliterated as 'original people') are the indigenous minority inhabitants of Peninsular Malaysia. The total population of Orang Asli is 178,197 throughout Peninsular Malaysia, comprising only $0.6 \%$ of the total population in Malaysia [26]. Despite intensive efforts by the government and private sectors to improve the quality of life of aboriginal communities throughout 59 years of independence (since 1957), little success has been achieved due to the 


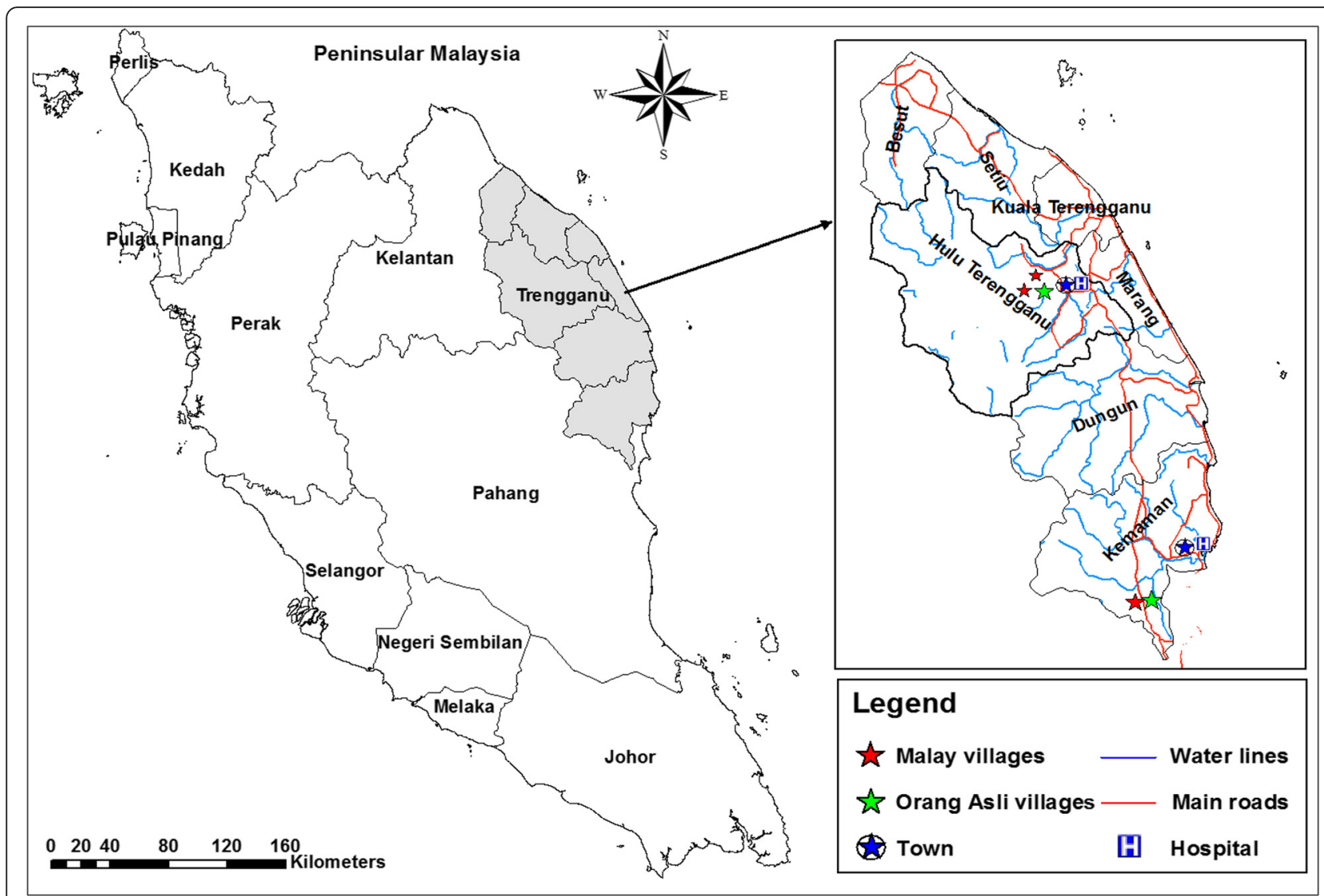

Fig. 1 Map showing the location of Terengganu State and the villages involved in the study. The map was created using the Esri ArcMap 10.2.1 software

adherence of the Orang Asli people to their jungle habitats. On the other hand, Malay communities are better in terms of environment cleanliness and housing conditions.

The minimum sample size required for this study was calculated according to the formula provided by Lwanga \& Lemeshow [27]. At a $5 \%$ level of significance and a $95 \%$ confidence level, the minimum number of participants required for the study was estimated at 276 (138 participants from each population), assuming that the prevalence of IPIs among Orang Asli children was about $90 \%$ as previously reported [21, 25], and about $10 \%$ among rural Malay population. However, at the villages, all children who were present during our visit were invited to participate in the study (universal sampling).

Overall, 443 eligible children have agreed voluntarily to participate in the study. However, the 340 children who delivered suitable samples for examination with complete questionnaire data were included in this study. Of these 340 participants, 165 children $(77$ girls and 88 boys) were from Orang Asli settlements (Senoi tribe) and 175 children (99 girls and 76 boys) were from Malay communities. Throughout many visits to the study areas, most of the Orang Asli children were observed playing outside without wearing shoes or slippers. Also, it was observed that poverty prevails in these areas with poor housing and living conditions. Better conditions in terms of housing and sanitary facilities and personal hygiene practices were observed in Malay rural communities. Some of the children play and swim in the streams/pools after school and in their leisure time.

\section{Questionnaire survey}

A pre-tested questionnaire was used to collect the information on the demographic (age, gender and family size), socioeconomic (education attainment, occupation, household income), behavioural (personal hygiene such as hand washing, wearing shoes when going outside and consumption of raw fruits and vegetables), medical history (whether the participant has taken anthelminthic drugs, history of chronic diseases) and environmental factors (sanitation and living condition characteristics such as type of water supply, latrine system, garbage disposal system and presence of domestic animals) which were used to assess the potential risk factors of IPIs.

Moreover, the questionnaire includes questions on respondents' KAP towards IPIs. Questions on the knowledge about symptoms, preventive measures and mode of transmission of IPIs were open-ended questions to 
avoid guessing which may give a false impression of the knowledge of the participant. However, the questions pertaining to the practices and daily activities were provided with multiple-choice answers to assess the frequency of doing these activities or actions. The children and their parents, who agreed voluntarily to participate, were interviewed face-to-face in their home settings by two research assistants from the Department of Parasitology, University of Malaya who were trained on how to administer the questionnaire for the purpose of this study.

\section{Parasitological examination of faecal samples}

The children were given a clearly labelled, wide mouth screw-cap containers and were instructed to bring their early morning stool samples the next day. An accurate demonstration of how to collect the stool samples was made to the children so as to avoid possible contamination in the course of collection at home. The containers were placed into zipped plastic bags, kept in a protected ice box and transported (within $8 \mathrm{~h}$ of collection) for examination at the Department of Parasitology, University of Malaya.

The examination was carried out by using different techniques, direct smear (wet mount) was applied on all samples and then formalin-ether sedimentation technique was used to increase the detection rates especially when the parasites are in few numbers [28]. Moreover, KatoKatz technique was used for egg counts to estimate the intensity of infections and the results were recorded as eggs per gram of stool (EPG) [29]. Intensity of infection was graded as heavy, moderate, or light according to the criteria proposed by the World Health Organization [29]. For Ascaris, Trichuris and hookworm infections, egg counts of $\geq 50,000$ EPG, $\geq 10,000$ EPG and $\geq 4000$ EPG, respectively, are regarded as heavy infections while egg counts of 1-4999 EPG, 1-999 EPG and 1-1999 EPG, respectively, are regarded as light infections [29]. In addition, Harada-Mori culture technique was applied to detect hookworm larvae in light infections [30].

A suitable amount (approximately $10 \mathrm{gm}$ ) of each faecal sample was mixed thoroughly and fixed in polyvinyl alcohol (PVA) for the detection of protozoans (Giardia, Entamoeba and Blastocystis) using trichrome staining technique [31, 32]. Moreover, faecal smears were prepared and stained with modified Ziehl-Neelsen stain, according to Henriksen \& Pohlenz [33], for the detection of Cryptosporidium oocysts. In addition, approximately $50 \mathrm{mg}$ of faeces were inoculated into a $15-\mathrm{ml}$ screw-capped tube containing $5.0 \mathrm{ml}$ of complete Jones' medium and incubated at $37{ }^{\circ} \mathrm{C}$ [34]. About $4.0 \mathrm{ml}$ of the medium in each of these tubes was replaced with similar amount of the new complete Jone's medium every alternate day starting from day 2 of cultivation. The presence of Blastocystis was observed by using light microscopy, daily for 14 days of cultivation. Different sizes of Blastocystis cells $(2-15 \mu \mathrm{m})$ were seen as vacuolar (most common), granular, amoeboid (vacuolar or granular with pseudopodia) and cyst forms [34, 35]. Overall, the samples were considered as positive by the detection of eggs/larvae/cysts/trophozoites/oocysts using any of these seven techniques.

\section{Data analysis}

Data were double-entered by two different researchers into Microsoft Office Excel 2007 spreadsheets. Then, a third researcher cross-checked the two data sets for accuracy and created a single data set. Data analysis was made using IBM SPSS Statistics, version 18.0 (IBM Corporation, New York, NY, USA). Demographic, socioeconomic, environmental and behavioural characteristics as well as KAP variables were treated as categorical variables and presented as frequencies and percentages. Pearson's Chisquare $\left(\chi^{2}\right)$ test or Fisher's exact test were used where appropriate to examine the difference in proportions between groups and to test the association of polyparasitism prevalence as the dependent variable with the demographic (age, gender and family size), socioeconomic (parents' educational and employment status, household monthly income, source of drinking water, presence of functioning toilet in the house, garbage disposal and presence of domestic animals in the households) and personal hygiene practices (washing hands before eating and after defecation, washing fruits and vegetables before consumption, wearing shoes when outside, eating soil (geophagy), boiling/filtering drinking water, cutting nails periodically and indiscriminate defecation) as the explanatory variables. All variables were coded in a binary manner as dummy variables, eg polyparasitism (positive $=1$, negative $=0$ ); gender ( boys $=1$, girls $=0$ ), and so on. Odd ratios (OR) and $95 \%$ confidence intervals (CI) were also computed. Likewise, to control the variation in number of children in households, weight cases, derived by the sampling fraction 1/number of participated children from each family, was used to analyse the KAP data.

In order to identify the risk factors significantly associated with intestinal polyparasitism (coded as $1=$ polyparasitism, $0=$ monoparasitism and uninfected), all variables that showed associations with $P \leq 0.25$ in the univariate analyses were used to develop a multivariate logistic regression model as suggested by Bendel \& Afifi [36]. Moreover, sex variable was also included in the multivariable analysis as it has been considered as an important behavioural modifying factor [37]. Population attributable risk fraction (PARF) was calculated for significantly associated risk factors [38]. A $P$ value of $<0.05$ was considered to be statistically significant.

\section{Ethical statement}

The study protocol was approved by the Ethics Committee of the University Malaya Medical Centre (UMMC), Malaysia (Reference Number: 638.36). Permission was 
also obtained from the Department of Orang Asli Development (JAKOA), Ministry of Rural and Regional Development, Kuala Lumpur. At the study area, meetings were held with the heads of villages and parents to provide information about the objectives and protocol of the study and their permission to conduct the study was obtained. The children and their parents/guardians were informed that the procedures used did not pose any potential risk and their identities and personal data will be kept strictly confidential. They were informed that their participation was voluntarily and they could withdraw from the study at any time without citing any reason whatsoever. Written and signed or thumb-printed informed consent was obtained from parents or guardians on behalf of their children and these procedures were approved by the Medical Ethics Committee of the University of Malaya Medical Centre.

\section{Results}

\section{General characteristics of the households}

Three hundred and forty children (165 Orang Asli and 175 Malay) with a mean age of 7.9 years (standard deviation,
$\mathrm{SD}=2.8$ ) from five villages participated in this study. Although both communities were close to each other, notable differences in the socioeconomic, cultural, environmental and personal hygiene practices were observed (Table 1). With regards to the Orang Asli, about half of the fathers $(49.1 \%)$ and mothers $(58.2 \%)$ had at least primary education. Poverty prevails in the Orang Asli communities in which about two-thirds of the participants belonged to families with low household monthly income (< RM500). Less than one-quarter of the fathers $(23.6 \%)$ and mothers $(17.6 \%)$ were working and most were engaged in forestry, agriculture and fishing. All of the houses were small, singlestorey concrete terrace houses built by the Terengganu government to replace the old bamboo and wooden houses. However, only about half of the houses had piped water supply and electricity, and only $21.8 \%$ had functioning toilet facilities.

With regard to Malay communities, almost all fathers and mothers were educated and had at least a primary education. Similarly, the majority of the families $(80.6 \%)$ had a household monthly income of $>$ RM500. Moreover,

Table 1 General characteristics of children who participated in the study $(n=340)$

\begin{tabular}{|c|c|c|c|}
\hline \multirow[t]{2}{*}{ Characteristics } & Orang Asli & Malay & Overall \\
\hline & $n(\%)$ & $n(\%)$ & $n(\%)$ \\
\hline No. of participants & $165(48.5)$ & $175(51.5)$ & $340(100.0)$ \\
\hline \multicolumn{4}{|l|}{ Age groups (years) } \\
\hline$\leq 5$ & $51(30.9)$ & $45(25.7)$ & $96(28.2)$ \\
\hline $6-10$ & $64(38.8)$ & $81(46.3)$ & $145(42.6)$ \\
\hline$>10$ & $50(30.3)$ & $49(28.0)$ & 99 (29.2) \\
\hline \multicolumn{4}{|l|}{ Gender } \\
\hline Boys & $88(53.3)$ & $76(43.4)$ & $164(48.2)$ \\
\hline Girls & $77(46.7)$ & 99 (56.6) & $176(51.8)$ \\
\hline \multicolumn{4}{|l|}{ Socioeconomic status } \\
\hline \multicolumn{4}{|l|}{ Father's education level } \\
\hline Never went to school & $84(50.9)$ & $4(2.3)$ & $88(25.9)$ \\
\hline Primary education & $63(38.2)$ & $72(41.1)$ & $135(39.7)$ \\
\hline Secondary education & $18(10.9)$ & $99(56.6)$ & $117(34.4)$ \\
\hline \multicolumn{4}{|l|}{ Mother's education level } \\
\hline Never went to school & $69(41.8)$ & $3(1.7)$ & $72(21.2)$ \\
\hline Primary education & $82(49.7)$ & $93(53.1)$ & $175(51.5)$ \\
\hline Secondary education & $14(8.5)$ & $79(45.1)$ & $93(27.4)$ \\
\hline Low monthly household income (< RM500) & $106(64.2)$ & $34(19.4)$ & $140(41.2)$ \\
\hline Working fathers & $39(23.6)$ & $135(77.1)$ & $174(51.2)$ \\
\hline Working mothers & $29(17.6)$ & $41(23.4)$ & $70(20.6)$ \\
\hline Large family size ( $\geq 7$ members) & $58(35.2)$ & $89(50.9)$ & $147(43.2)$ \\
\hline Piped water supply & $91(55.2)$ & $175(100.0)$ & $266(78.2)$ \\
\hline Electricity & $83(50.3)$ & $175(100.0)$ & $258(75.9)$ \\
\hline Presence of toilet in house & $36(21.8)$ & $175(100.0)$ & $211(62.1)$ \\
\hline
\end{tabular}

Abbreviations: All values are number (\%). RM Malaysian Ringgit; (US\$ $1=$ RM 4.20) 
77.1 and $23.4 \%$ of the children had working fathers and working mothers, respectively, who were employed as workers on oil palm plantations, farms, livestock preservation, government and private sectors. The houses were large and built of timber and concrete. All of the houses had toilet facilities, piped-in water and electricity.

\section{Prevalence of IPIs}

The prevalence of IPIs among the participants is shown in Table 2. In general, $56.5 \%(192 / 340)$ of the participants tested positive for at least one parasite species. Of these, $90.3 \%(149 / 165)$ were Orang Asli and $24.6 \%$ (43/ $175)$ were Malay $(P<0.001)$. Among the Orang Asli, $T$. trichiura exhibited the highest prevalence (78.8\%), followed by A. lumbricoides (53.9\%) and Blastocystis sp. (34.5\%). Similarly, Blastocystis sp. showed the highest prevalence (25.9\%) among Malay communities, followed by T. trichiura (9.7\%) and G. duodenalis (8.6 \%). Overall, $71.9 \%(138 / 192)$ of the infected participants (ie $40.6 \%$ of all children) had polyparasitism (the concurrent infection by $\geq$ two parasite species), with 34.1 and $41.3 \%$ of them infected with two or three parasites, respectively. Among these infected individuals, the prevalence of polyparasitism was significantly higher among
Orang Asli children compared to their Malay peers (75.8 vs $58.1 \%$; $P=0.010$ ).

With regard to the intensity of STH infections, the results showed that almost two-thirds $(66.2 \%)$ and onethird $39.3 \%$ of the Trichuris and Ascaris infections, respectively, among Orang Asli, were of moderate-toheavy intensity (mean EPG of $\geq 1000$ for Trichuris and $\geq$ 5000 for Ascaris), whereas $17.9 \%$ of the hookworm infections were of moderate intensity (mean EPG between 2000 and 3999). On the other hand, only 2 (11.8 \%) and 1 (16.7 \%) Malay children had moderate-to-heavy intensity Trichuris and Ascaris infections, respectively.

\section{Risk factors of polyparasitism}

Associations of polyparasitism with demographic, socioeconomic, environmental and personal hygiene factors among the Orang Asli and Malay children were investigated and the results are presented in Table 3 . In the Orang Asli communities, the results showed that the prevalence of polyparasitism was significantly higher among children who lived in families with $\geq 7$ members compared with those living in smaller families with $<7$ members (81.0 vs $61.7 \% ; P=0.011)$. Likewise, children of mothers with a low educational level ( $<6$ years) had a significantly higher polyparasitism prevalence compared

Table 2 Prevalence of intestinal parasitic infections by parasite species and number of infections among Orang Asli and Malay in Terengganu $(n=340)$

\begin{tabular}{|c|c|c|c|c|c|}
\hline Infections & $\begin{array}{l}\text { Orang Asli } \\
n(\%)\end{array}$ & $\begin{array}{l}\text { Malay } \\
n(\%)\end{array}$ & $\begin{array}{l}\text { Overall } \\
n(\%)\end{array}$ & $x^{2}$ & $P$-value \\
\hline Overall infections & $149(90.3)$ & $43(24.6)$ & $192(56.5)$ & 149.275 & $<0.001^{*}$ \\
\hline \multicolumn{6}{|l|}{ Parasite species } \\
\hline Trichuris trichiura & $130(78.8)$ & $17(9.7)$ & $147(43.2)$ & 165.101 & $<0.001^{*}$ \\
\hline Ascaris lumbricoides & 89 (53.9) & $6(3.4)$ & $95(27.9)$ & 107.617 & $<0.001^{*}$ \\
\hline Hookworm & $39(23.6)$ & $1(0.6)$ & $40(11.8)$ & 43.524 & $<0.001^{*}$ \\
\hline Giardia duodenalis & $24(14.5)$ & $15(8.6)$ & $39(11.5)$ & 2.985 & 0.084 \\
\hline Entamoeba spp. & $24(14.5)$ & $14(8.0)$ & $38(11.2)$ & 3.665 & 0.056 \\
\hline Cryptosporidium spp. & $7(4.2)$ & $4(2.3)$ & $11(3.2)$ & 1.039 & 0.308 \\
\hline Blastocystis sp. & $57(34.5)$ & $31(17.7)$ & $88(25.9)$ & 12.541 & $<0.001^{*}$ \\
\hline \multicolumn{6}{|l|}{ Type of infection $(n=192)^{\mathrm{a}}$} \\
\hline Monoparasitism & $35(23.5)$ & $18(41.9)$ & $50(26.6)$ & - & - \\
\hline Polyparasitism & $113(75.8)$ & $25(58.1)$ & $138(71.9)$ & 6.654 & $0.010^{*}$ \\
\hline \multicolumn{6}{|c|}{$\begin{array}{l}\text { No. and type of polyparasitism } \\
(n=138)^{b}\end{array}$} \\
\hline Two parasite species & $39(34.5)$ & $8(32.0)$ & $47(34.1)$ & 0.058 & 0.810 \\
\hline Three parasite species & $43(38.1)$ & $14(56.0)$ & $57(41.3)$ & 2.720 & 0.099 \\
\hline Four parasite species & $27(23.9)$ & $3(12.0)$ & $30(21.7)$ & 1.702 & 0.192 \\
\hline Five parasite species & $4(3.5)$ & $0(0)$ & $4(2.9)$ & 0.911 & 0.340 \\
\hline
\end{tabular}

Abbreviations: $X^{2}$ Chi-square test statistic

* Significant difference between the two groups $(P<0.05)$

${ }^{a} n=192$, children who were infected with at least one parasite species

${ }^{b} n=138$, children who were infected with two or more parasite species 
Table 3 Univariate analysis of factors associated with polyparasitism among Orang Asli and Malay children in Terengganu ( $n=340)$

\begin{tabular}{|c|c|c|c|c|c|c|c|c|}
\hline \multirow[t]{2}{*}{ Variable } & \multicolumn{2}{|l|}{ Orang Asli } & \multirow[b]{2}{*}{ OR (95 \% Cl) } & \multirow[b]{2}{*}{$P$-value } & \multicolumn{2}{|l|}{ Malay } & \multirow[b]{2}{*}{ OR $(95 \% \mathrm{Cl})$} & \multirow[b]{2}{*}{$P$-value } \\
\hline & No. examined & $\%$ infected & & & No. examined & $\%$ infected & & \\
\hline \multicolumn{9}{|l|}{ Age } \\
\hline School-age ( $\geq 6$ years) & 98 & 71.4 & $1.40(0.72-2.71)$ & 0.325 & 130 & 13.8 & $0.87(0.34-2.25)$ & 0.778 \\
\hline Preschool (< 6 years) & 67 & 64.2 & 1 & & 45 & 15.6 & 1 & \\
\hline \multicolumn{9}{|l|}{ Gender } \\
\hline Boys & 88 & 73.9 & $1.71(0.88-3.31)$ & 0.112 & 76 & 19.7 & $2.19(0.92-5.19)$ & 0.071 \\
\hline Girls & 77 & 62.3 & 1 & & 99 & 10.1 & 1 & \\
\hline \multicolumn{9}{|l|}{ Family size } \\
\hline$\geq 7$ members (large) & 58 & 81.0 & $2.65(1.24-5.70)$ & $0.011^{*}$ & 89 & 18.0 & $1.88(0.78-4.51)$ & 0.156 \\
\hline$<7$ members & 107 & 61.7 & 1 & & 86 & 10.5 & 1 & \\
\hline \multicolumn{9}{|l|}{ Father's educational level } \\
\hline Non educated & 84 & 71.4 & $1.32(0.68-2.55)$ & 0.407 & 4 & 25.0 & $2.04(0.21-20.45)$ & 0.536 \\
\hline Educated ( $\geq 6$ years) & 81 & 65.4 & 1 & & 171 & 14.0 & 1 & \\
\hline \multicolumn{9}{|l|}{ Mother's educational level } \\
\hline Non educated & 69 & 79.7 & $2.57(1.26-5.26)$ & $0.009^{*}$ & 3 & 33.3 & $3.08(0.27-35.34)$ & 0.342 \\
\hline Educated ( $\geq 6$ years) & 96 & 60.4 & 1 & & 172 & 14.0 & 1 & \\
\hline \multicolumn{9}{|l|}{ Father's employment status } \\
\hline Not working & 126 & 71.4 & $1.74(0.83-3.67)$ & 0.143 & 40 & 17.5 & $1.38(0.53-3.58)$ & 0.508 \\
\hline Working & 39 & 59.0 & 1 & & 135 & 13.3 & 1 & \\
\hline \multicolumn{9}{|l|}{ Mother's employment status } \\
\hline Not working & 136 & 69.1 & $1.18(0.51-2.75)$ & 0.705 & 134 & 10.4 & $0.32(0.13-0.77)$ & $0.009^{*}$ \\
\hline Working & 29 & 65.5 & 1 & & 41 & 26.8 & 1 & \\
\hline \multicolumn{9}{|l|}{ Household monthly income } \\
\hline$<$ RM 500 & 106 & 68.9 & $1.05(0.53-2.08)$ & 0.887 & 34 & 26.5 & $2.81(1.12-7.08)$ & $0.024^{*}$ \\
\hline$\geq$ RM 500 & 59 & 67.8 & 1 & & 141 & 11.3 & 1 & \\
\hline \multicolumn{9}{|l|}{ Presence of toilet in house } \\
\hline No & 129 & 72.9 & $2.40(1.12-5.14)$ & $0.022^{*}$ & 0 & 0 & na & na \\
\hline Yes & 36 & 52.8 & 1 & & 175 & 14.3 & 1 & \\
\hline \multicolumn{9}{|l|}{ Source of drinking water } \\
\hline Unsafe source (river, rain) & 74 & 83.8 & $4.05(1.93-8.53)$ & $<0.001^{*}$ & 0 & 0 & na & na \\
\hline Safe source (pipe) & 91 & 56.0 & 1 & & 175 & 14.3 & 1 & \\
\hline \multicolumn{9}{|l|}{ Presence of domestic animals } \\
\hline Yes & 109 & 77.1 & $3.13(1.57-6.23)$ & $0.001^{*}$ & 117 & 18.8 & $4.25(1.22-14.84)$ & $0.015^{*}$ \\
\hline No & 56 & 51.8 & & & 58 & 5.2 & 1 & \\
\hline \multicolumn{9}{|l|}{ Washing hands before eating } \\
\hline No & 56 & 71.4 & $1.23(0.61-2.49)$ & 0.560 & 22 & 13.6 & $0.94(0.26-3.45)$ & 0.926 \\
\hline Yes & 109 & 67.0 & 1 & & 153 & 14.4 & 1 & \\
\hline \multicolumn{9}{|l|}{ Washing hands after defecation } \\
\hline No & 63 & 63.5 & $0.69(0.35-1.35)$ & 0.278 & 15 & 20.0 & $1.57(0.41-6.01)$ & 0.508 \\
\hline Yes & 102 & 71.6 & 1 & & 160 & 13.8 & 1 & \\
\hline \multicolumn{9}{|c|}{ Washing hands after playing with soil } \\
\hline No & 71 & 80.3 & $2.76(1.35-5.65)$ & $0.005^{*}$ & 39 & 15.4 & $1.12(0.41-3.03)$ & 0.824 \\
\hline Yes & 94 & 59.6 & 1 & & 136 & 14.0 & 1 & \\
\hline
\end{tabular}


Table 3 Univariate analysis of factors associated with polyparasitism among Orang Asli and Malay children in Terengganu ( $n=340)$ (Continued)

\begin{tabular}{|c|c|c|c|c|c|c|c|c|}
\hline \multicolumn{9}{|c|}{ Indiscriminate defecation } \\
\hline Yes & 135 & 71.9 & $2.23(1.01-5.02)$ & $0.041^{*}$ & 0 & 0 & na & na \\
\hline No & 30 & 53.3 & 1 & & 175 & 14.3 & 1 & \\
\hline \multicolumn{9}{|c|}{ Eating soil habit (geophagy) } \\
\hline Yes & 29 & 65.5 & $0.85(0.36-1.98)$ & 0.705 & 11 & 18.2 & $1.36(0.23-6.71)$ & 0.703 \\
\hline No & 136 & 69.1 & 1 & & 164 & 14.0 & 1 & \\
\hline \multicolumn{9}{|l|}{ Garbage disposal } \\
\hline Indiscriminately & 57 & 66.7 & $0.88(0.44-1.75)$ & 0.715 & 23 & 17.4 & $1.31(0.41-4.24)$ & 0.648 \\
\hline Collected & 108 & 69.4 & 1 & & 152 & 13.8 & 1 & \\
\hline \multicolumn{9}{|c|}{ Cutting nails periodically } \\
\hline No & 52 & 69.2 & $1.05(0.52-2.14)$ & 0.889 & 25 & 12.0 & $0.79(0.22-2.88)$ & 0.724 \\
\hline Yes & 113 & 68.1 & 1 & & 150 & 14.7 & 1 & \\
\hline \multicolumn{9}{|c|}{ Wearing shoes when go outside } \\
\hline No & 100 & 80.0 & $3.88(1.95-7.74)$ & $<0.001^{*}$ & 1 & 0 & na & na \\
\hline Yes & 65 & 50.8 & 1 & & 174 & 14.4 & 1 & \\
\hline \multicolumn{9}{|c|}{ Washing fruits before eating } \\
\hline No & 101 & 71.3 & $1.39(0.71-2.72)$ & 0.330 & 19 & 15.8 & $1.14(0.31-4.25)$ & 0.843 \\
\hline Yes & 64 & 64.1 & 1 & & 156 & 14.1 & 1 & \\
\hline \multicolumn{9}{|c|}{ Washing vegetables before eating } \\
\hline No & 77 & 77.9 & $2.33(1.17-4.63)$ & $0.015^{*}$ & 23 & 13.0 & $0.89(0.24-3.24)$ & 0.855 \\
\hline Yes & 88 & 60.2 & 1 & & 152 & 14.5 & 1 & \\
\hline \multicolumn{9}{|c|}{ Boiling/filtering water before drinking } \\
\hline No & 131 & 70.2 & $1.46(0.67-3.21)$ & 0.344 & 55 & 16.4 & $1.27(0.52-3.09)$ & 0.595 \\
\hline Yes & 34 & 61.8 & 1 & & 120 & 13.3 & 1 & \\
\hline
\end{tabular}

Abbreviations: RM Malaysian Ringgit; (US\$ $1=\mathrm{RM} 3.2$ ); OR odds ratio, $\mathrm{Cl}$ confidence interval, na not applicable

* Significant association $(P<0.05)$

with children of mothers with at least 6 years of formal education (79.7 vs 60.4\%; $P=0.009)$. Moreover, children who lived in houses without toilet facilities (72.9 vs $52.8 \% ; P=0.022$ ), those who used unsafe sources of drinking water $(83.8$ vs $56.0 \% ; P<0.001)$ and those who have domestic animals (mostly cats and/or dogs) in their households (77.1 vs $51.8 \%$; $P=0.001$ ) had a higher prevalence compared with their counterparts. With regard to personal hygiene factors, the results showed that polyparasitism was significantly higher among children who practiced indiscriminate/open defecation compared to those who used toilets (71.9 vs $53.3 \%$; $P=0.041$ ), and among children who walked barefooted when outside their houses compared to those who wore shoes or slippers (80.0 vs $50.8 \% ; P<0.001)$. Likewise, children who did not wash their hands after playing with soil $(P=0.005)$ and those who did not wash vegetables before consuming them $(P=0.015)$ had a significantly higher prevalence of polyparasitism compared to their counterparts.

With regards to Malay communities, Table 3 shows that polyparasitism was significantly lower among children of mothers who did not work compared with children of working mothers (10.4 vs $26.8 \%$; $P=0.009)$. Moreover, children from families with a low household monthly income (< RM500) (26.5 vs $11.3 \%$; $P=0.024$ ) and those who have domestic animals in their households (18.8 vs $5.2 \% ; P=0.015)$ had a higher prevalence rate compared to their counterparts.

Table 4 shows that seven variables were retained by the multivariable logistic regression analysis as the significant risk factors of polyparasitism among the studied Orang Asli children. The Hosmer-Lemeshow test, used for the inferential goodness-of-fit test, showed that the model fit the data well $\left(\chi^{2}=7.108, d f=8, P=0.525\right)$. Children of non-educated mothers were found to have higher odds of polyparasitism compared with children of mothers with at least a primary education (OR 4.35; 95 \% CI: 1.72-11.19). Similarly, children who drank unsafe drinking water and those who did not wear shoes/ slippers when outside had about three times the odds of having polyparasitism compared to their counterparts. Likewise, having domestic animals in the household was 
Table 4 Multivariate analysis of factors associated with polyparasitism among Orang Asli and Malay children in Terengganu ( $n=340)$

\begin{tabular}{|c|c|c|c|c|}
\hline Variable & $\begin{array}{l}\text { Orang Asli } \\
\text { a-OR (95 \% Cl) }\end{array}$ & $P$-value & $\begin{array}{l}\text { Malay } \\
\text { a-OR (95 \% Cl) }\end{array}$ & $P$-value \\
\hline \multicolumn{5}{|l|}{ Demographic factors } \\
\hline Gender (boys) & $1.38(0.58-3.26)$ & 0.470 & $2.36(0.92-6.09)$ & 0.075 \\
\hline Family size ( $\geq 7$ members; large) & $2.32(0.88-5.91)$ & 0.089 & $2.47(0.98-7.74)$ & 0.052 \\
\hline \multicolumn{5}{|l|}{ Socioeconomic factors } \\
\hline Mother's educational level (< 6 years) & $4.35(1.72-11.19)$ & $0.001^{*}$ & - & - \\
\hline Father's employment status & $1.80(0.70-4.65)$ & 0.224 & - & - \\
\hline Mother's employment status (not working) & - & - & $0.34(0.12-0.95)$ & $0.039^{*}$ \\
\hline Household monthly income (< RM 500) & - & - & $2.16(0.78-4.94)$ & 0.138 \\
\hline Presence of toilet in house (no) & $1.64(0.71-2.30)$ & 0.063 & - & - \\
\hline Source of drinking water (unsafe water) & $3.61(1.37-7.50)$ & $0.009^{*}$ & - & - \\
\hline Presence of domestic animals (yes) & $4.30(1.67-11.08)$ & $0.003^{*}$ & $3.81(1.04-13.75)$ & $0.045^{*}$ \\
\hline \multicolumn{5}{|l|}{ Personal hygiene factors } \\
\hline Washing hands after playing with soil (no) & $4.26(1.59-11.42)$ & $0.004^{*}$ & - & - \\
\hline Washing vegetables before eating (no) & $3.52(1.40-8.87)$ & $0.008^{*}$ & - & - \\
\hline Wearing shoes when outside (no) & $2.94(1.15-7.53)$ & $0.025^{*}$ & - & - \\
\hline Indiscriminate defecation (yes) & $3.13(1.05-9.35)$ & $0.010^{*}$ & - & - \\
\hline
\end{tabular}

Abbreviations: $a-O R$ adjusted odds ratio, $C l$ confidence interval

*Significant predictors of polyparasitism $(P<0.05)$

retained as a significant risk factor of polyparasitism and was found to increase the odds of infection by almost four times (95 \% CI: 1.67-11.08). It was found that not washing vegetables before consumption, not washing hands after playing in the soil and indiscriminate defecation increased the Orang Asli children's odds for polyparasitism by $3.5,4.3$ and 3.1 times, respectively, compared with their counterparts.

Population attributable risk fraction (PARF) analysis showed that the number of polyparasitism cases among Orang Asli children could be reduced by 25.9, 22.1, 13.0 and $12.1 \%$ if all children practiced good standards of personal hygiene, specifically by wearing shoes when going outside the house, using toilets for defecation (avoiding open defecation), washing their hands after playing in the soil and washing vegetables before consumption. Moreover, 23.1, 18.2 and $11.8 \%$ of the polyparasitism cases could be avoided if there are no domestic animals at the households, the population had safe drinking water and the mothers had at least a primary education.

With regards to Malaya participants, three factors were confirmed by multiple logistic regression model analyses as the significant predictors of polyparasitism (Table 4). Children who have domestic animals at their household had 3.8 odds of having polyparasitism compared with those who do not have domestic animals. Similarly, children of mothers who do not work were found to have a lower risk of polyparasitism compared with children of working mothers (OR 0.34; 95 \% CI: 0.12-0.95). Overall, PARF analysis showed that the number of polyparasitism cases could be reduced among the Malay children by 26.9 and $24.7 \%$ when proper care is given to the children of working mothers and without domestic animals in the households, respectively.

\section{Knowledge about IPIs, their signs and symptoms, transmission and prevention}

A total of 160 householders (104 Orang Asli and 83 Malay) participated in face-to-face interviews to fill in the questionnaire on their KAP towards IPIs. The general results of the knowledge of the respondents about IPIs transmission, signs and symptoms and prevention is shown in Table 5. It was found that almost all Malay respondents $82(98.8 \%)$ had heard about the IPIs compared to $75.0 \%(78 / 104)$ of the Orang Asli participants $(P<0.001)$. Of those who had prior knowledge of IPIs, a significant percentage of the Malay respondents indicated the self-reading or Internet search $(P<0.001)$ and other people $(P=0.012)$ as the sources of their knowledge about IPIs compared to their Orang Asli peers. However, the percentage of Orang Asli respondents who knew about IPIs from the health clinics was significantly higher than the Malay (56.4 vs $35.4 \% ; P=0.008$ ).

In general, $96.3,97.6$ and $98.8 \%$ of the Malay respondents were able to mention at least one symptom of IPIs, one mode of transmission and one preventive measure against IPIs, respectively, compared to 75.6, 52.6 and $64.1 \%$ of the Orang Asli respondents $(P<0.001)$. The percentages of respondents who mentioned diarrhoea (42.7 vs $11.5 \%$; $P<0.001)$ and loss of weight $(17.1$ vs $5.2 \% ; P=$ 
Table 5 Knowledge about IPIs symptoms, transmission and prevention among Orang Asli and Malay participants who had prior knowledge on IPIs $(n=160)$

\begin{tabular}{|c|c|c|c|c|c|c|}
\hline \multirow[t]{2}{*}{ Variables } & \multicolumn{2}{|c|}{$\begin{array}{l}\text { Orang Asli } \\
n=104\end{array}$} & \multicolumn{2}{|c|}{$\begin{array}{l}\text { Malay } \\
n=83\end{array}$} & \multirow[t]{2}{*}{$x^{2}$} & \multirow[t]{2}{*}{$P$-value } \\
\hline & $n$ & $(\%)$ & $n$ & (\%) & & \\
\hline Heard about IPIs $(n=187)$ & 78 & 75.0 & 82 & 98.8 & 21.157 & $<0.001^{*}$ \\
\hline \multicolumn{7}{|l|}{ Source of information } \\
\hline Health clinic/hospitals & 44 & 56.4 & 29 & 35.4 & 7.136 & $0.008^{*}$ \\
\hline Mass media & 1 & 1.3 & 5 & 6.1 & - & $0.211^{a}$ \\
\hline Other people & 6 & 7.7 & 18 & 22.0 & 6.375 & $0.012^{*}$ \\
\hline School & 4 & 5.1 & 10 & 12.2 & 2.500 & 0.114 \\
\hline Self reading/internet & 0 & 0.0 & 13 & 15.9 & 13.459 & $<0.001^{*}$ \\
\hline Do not remember & 18 & 23.1 & 9 & 11.0 & 4.173 & $0.041^{*}$ \\
\hline \multicolumn{7}{|l|}{ Signs and symptoms } \\
\hline Abdominal pain & 32 & 41.0 & 30 & 36.6 & 0.332 & 0.564 \\
\hline Abdominal distension & 3 & 3.8 & 8 & 9.8 & 2.181 & 0.140 \\
\hline Diarrhoea & 9 & 11.5 & 35 & 42.7 & 19.448 & $<0.001^{*}$ \\
\hline Vomiting & 8 & 10.3 & 11 & 13.4 & 0.381 & 0.537 \\
\hline Loss of appetite & 14 & 17.9 & 14 & 17.1 & 0.021 & 0.884 \\
\hline Pale face & 1 & 1.3 & 6 & 7.3 & - & $0.062^{\mathrm{a}}$ \\
\hline Body weakness & 7 & 9.0 & 10 & 12.2 & 0.437 & 0.509 \\
\hline Fever & 5 & 6.4 & 9 & 11.0 & 1.044 & 0.307 \\
\hline Itching & 20 & 25.6 & 8 & 9.8 & 6.987 & $0.008^{*}$ \\
\hline Loss of weight & 4 & 5.2 & 14 & 17.1 & 5.581 & $0.018^{*}$ \\
\hline Do not know & 19 & 24.4 & 3 & 3.7 & 14.444 & $<0.001^{*}$ \\
\hline \multicolumn{7}{|l|}{ Transmission } \\
\hline Eating contaminated food & 19 & 24.4 & 42 & 51.2 & 12.226 & $<0.001^{*}$ \\
\hline Eating raw/undercooked food & 0 & 0.0 & 4 & 4.9 & 3.951 & $0.047^{*}$ \\
\hline Dirty hands & 15 & 19.2 & 49 & 59.8 & 27.355 & $<0.001^{*}$ \\
\hline Walking barefooted & 13 & 16.7 & 22 & 26.8 & 2.416 & 0.120 \\
\hline Drinking untreated water & 7 & 9.0 & 11 & 13.4 & 0.789 & 0.374 \\
\hline Playing with soil & 19 & 24.4 & 10 & 12.2 & 3.986 & $0.046^{*}$ \\
\hline Not cutting nails regularly & 2 & 2.6 & 5 & 6.1 & - & $0.444^{\mathrm{a}}$ \\
\hline Do not know & 37 & 47.4 & 2 & 2.4 & 43.908 & $<0.001^{*}$ \\
\hline \multicolumn{7}{|l|}{ Prevention } \\
\hline Taking deworming drugs & 23 & 29.5 & 28 & 34.1 & 0.400 & 0.527 \\
\hline Washing hands before eating & 14 & 17.9 & 45 & 54.9 & 23.421 & $<0.001^{*}$ \\
\hline Wearing shoes when outside the house & 10 & 12.8 & 17 & 20.7 & 1.784 & 0.182 \\
\hline Washing vegetables \& fruits before eating & 15 & 19.2 & 35 & 43.2 & 10.599 & $0.001^{*}$ \\
\hline Boiling/filtering drinking water & 10 & 12.8 & 19 & 23.5 & 3.014 & 0.083 \\
\hline Do not know & 28 & 35.9 & 1 & 1.2 & 32.394 & $<0.001^{*}$ \\
\hline
\end{tabular}

Abbreviations: $x^{2}$, Chi-square test statistic

*Significant difference between both groups $(P<0.05)$

${ }^{\text {a }}$ Fisher's exact test

0.018) were significantly higher among the Malay respondents, while the percentage of those who mentioned itching was significantly higher among the Orang Asli compared to the Malay (25.6 vs $9.8 \% ; P=0.008)$.
More than half of the Malay respondents had knowledge about the role of contaminated hands and contaminated food in transmitting IPIs compared to less than one-quarter of their Orang Asli counterparts $(P<0.001)$. 
Interestingly, eating raw and/or undercooked food was mentioned by only four Malay respondents (4.9 vs $0 \%$; $P=0.047$ ). However, a double percentage of the Orang Asli mentioned playing with the soil as a mode of transmission compared with the Malay (24.4 vs $12.2 \% ; P=0.046)$. In line with these results, $54.9 \%$ $(45 / 82)$ and $43.2 \%(35 / 82)$ of the Malay respondents mentioned washing their hand before eating and washing vegetables and fruits before consumption as preventive measures against IPIs compared to $17.9 \%$ (14/ $78)$ and $19.2 \%(15 / 78)$ of their Orang Asli counterparts $(P<0.001)$.

\section{Attitude and practices towards IPIs}

Results about the attitude and practices of respondents towards IPIs are shown in Table 6. Among those who had prior knowledge of IPIs, $87.8 \%(72 / 82)$ of the Malay and $61.5 \%$ (48/78) of the Orang Asli respondents considered the IPIs as harmful to people's health, while 11.5 and $2.4 \%$ of them, respectively, held the view that IPIs are not harmful $(P=0.001)$. Likewise, 46.3 and $20.5 \%$ of the Malay and Orang Asli respondents agreed that faeces are a source of infection, while $41.5 \%$ of the Malay and $56.4 \%$ of the Orang Asli had no idea about this point.

Regarding the hygiene practices, the results revealed that the Malay respondents had significantly higher levels of personal hygiene practices such as washing hands before having meals and after playing in the soil, wearing shoes when outside the house, washing vegetables/fruits before consumption and boiling/filtering drinking water compared with their Orang Asli counterparts $(P<0.001)$. In terms of treatment-seeking behaviour, going to the nearest clinic for treatment in case of diarrhoea and abdominal pain as a first line activity was significantly higher among the Malay than Orang Asli respondents (81.9 vs $55.8 \%$; $P<0.001)$, while significantly higher percentages of the Orang Asli tended to do nothing (17.3 vs $1.2 \%$; $P<0.001)$ for such symptoms compared to their Malay counterparts.

\section{Discussion}

To the best of our knowledge, this is the first study to provide information on the epidemiology of IPIs in Terengganu state and to compare the IPIs status between the Orang Asli and Malay populations residing the same rural areas. Our findings show that $90.3 \%$ of the Orang Asli children were found to be positive for at least one intestinal parasite species, with trichuriasis being the predominant infection. These findings are consistent with several previous studies among the Orang Asli communities in other states such as Pahang, Perak, Selangor and Kelantan [18, 21, 23, 25, 39]. Hence, this could be attributed to the same epidemiological characteristics of the Orang Asli throughout West Malaysia.
These include the poor housing conditions with the lack of access to safe drinking water and adequate sanitation, contaminated environment, high illiteracy rate and unhygienic practices by these people [24].

For protozoan infections, the present study showed that about one-third (34.5\%) of the Orang Asli children were infected with Blastocystis sp., while the prevalence of Entamoeba histolytica/dispar/moshkovskii (Entamoeba spp.) and G. duodenalis was $14.5 \%$ for both. Previous studies conducted among the Orang Asli children in different states showed a varying prevalence of infections with Blastocystis sp. ranging between 4.4 and $52.3 \%$ [32, 34, 40], Giardia ranging between 0.2 and $29.2 \%$ [13, 24] and Entamoeba spp. ranging between 1.0 and $61.0 \%$ [41]. Although the role of Blastocystis sp. in gastrointestinal disease is still controversial, there is an increasing body of evidence suggesting that Blastocystis is pathogenic, and its pathogenicity was found to be related to specific subtypes, parasite burden and host's immune status [42-44]. Moreover, many reports from Malaysia have claimed a pathogenic role of Blastocystis and clearly demonstrated that genotypes of Blastocystis can cloud parasite pathogenicity, particularly subtype 3 [45-48]. Hence, it seems currently wise to consider Blastocystis sp. among the intestinal parasites reported by the present study.

With regard to the Malay children, $24.6 \%$ of them were found to be infected with at least one parasite species, with blastocystosis being the predominant IPIs (17.7 \%), followed by trichuriasis $(9.7 \%)$ and giardiasis $(8.6 \%)$. Overall, the prevalence of STH infections was significantly lower in Malay children compared to their Orang Asli peers. This could be explained by the better housing and environmental conditions as well as the better knowledge and hygienic practices among Malay communities compared to the Orang Asli communities. Likewise, earlier studies among Malays in urban areas in Selangor state in 1984 and 1994 showed a very high rate of IPIs: 86.3 and $59.4 \%$, respectively $[49,50]$. However, a significant reduction in the prevalence of STH infections in the urban areas was reported and this could be explained by the great socioeconomic and infrastructural development in urban Malaysia during the past three decades [51, 52]. Overall, our findings are consistent with results of previous studies from other countries that revealed a significantly higher prevalence of IPIs among indigenous communities compared with nonindigenous groups $[53,54]$.

Our findings showed that the majority of the infected children had polyparasitism (71.9\%), with 34.1, 41.3 and $21.7 \%$ of the polyparasitism being concurrent infections with two, three and four parasite species, respectively. Previous studies in other countries, including the Philippines [55], Côte d'Ivoire [56], Kenya [57], Rwanda [58] and Cameroon [59] showed that polyparasitism was found to be the norm among the populations studied. 
Table 6 Attitude and perceived practices towards intestinal helminths among Orang Asli and Malay participants in Terengganu, Malaysia

\begin{tabular}{|c|c|c|c|c|c|c|}
\hline \multirow[t]{2}{*}{ Variables } & \multicolumn{2}{|c|}{ Orang Asli $(n=104)$} & \multicolumn{2}{|c|}{ Malay $(n=83)$} & \multirow[t]{2}{*}{$x^{2}$} & \multirow[t]{2}{*}{$P$-value } \\
\hline & $n$ & $(\%)$ & $n$ & (\%) & & \\
\hline \multicolumn{7}{|l|}{ Attitude $(n=160)$} \\
\hline Effects of intestinal parasitic infections & & & & & 14.992 & $0.001^{*}$ \\
\hline Harmful to peoples' health & 48 & 61.5 & 72 & 87.8 & & \\
\hline Not harmful to peoples' health & 9 & 11.5 & 2 & 2.4 & & \\
\hline Do not know & 21 & 26.9 & 8 & 9.8 & & \\
\hline Faeces as source of infections & & & & & 12.439 & $0.002^{*}$ \\
\hline Yes & 16 & 20.5 & 38 & 46.3 & & \\
\hline No & 18 & 23.1 & 10 & 12.2 & & \\
\hline Do not know & 44 & 56.4 & 34 & 41.5 & & \\
\hline \multicolumn{7}{|l|}{ Practices $(n=187)$} \\
\hline Washing hands before eating & 67 & 64.4 & 72 & 86.7 & 12.057 & $0.001^{*}$ \\
\hline Washing hands after defecation & 66 & 63.5 & 77 & 92.8 & 22.039 & $<0.001^{*}$ \\
\hline Washing hands after playing with soil & 61 & 58.7 & 64 & 77.1 & 7.093 & $0.008^{*}$ \\
\hline Washing vegetables before consumption & 55 & 52.9 & 73 & 88.0 & 26.284 & $<0.001^{*}$ \\
\hline Washing fruits before consumption & 44 & 42.3 & 72 & 86.7 & 38.705 & $<0.001^{*}$ \\
\hline Using safe sources for drinking water & 52 & 50.0 & 83 & 100 & 57.485 & $<0.001^{*}$ \\
\hline Wearing shoes when outside the house & 41 & 39.4 & 82 & 98.8 & 72.282 & $<0.001^{*}$ \\
\hline Boiling/filtering drinking water & 24 & 23.1 & 59 & 71.1 & 43.098 & $<0.001^{*}$ \\
\hline Using toilets for defecation & 17 & 16.3 & 83 & 100 & 129.839 & $<0.001^{*}$ \\
\hline Cutting fingernails regularly & 70 & 67.3 & 72 & 86.7 & 9.546 & $0.002^{*}$ \\
\hline Eating soil (geophagy) & 17 & 16.3 & 5 & 6.0 & 4.783 & $0.030^{*}$ \\
\hline \multicolumn{7}{|l|}{ Treatment-seeking behaviour for GIT symptoms } \\
\hline Go to clinic as a first line activity & 58 & 55.8 & 68 & 81.9 & 14.371 & $<0.001^{*}$ \\
\hline Go to traditional healer as a first line activity & 10 & 9.6 & 4 & 4.8 & 1.533 & 0.216 \\
\hline Use herbal remedies as a first line activity & 19 & 18.3 & 11 & 13.3 & 0.862 & 0.353 \\
\hline Do nothing & 18 & 17.3 & 1 & 1.2 & 15.895 & $<0.001^{*}$ \\
\hline
\end{tabular}

Abbreviations: $\chi^{2}$ Chi-square test statistic

*Significant difference between both groups $(P<0.05)$

Among the infected children, the present study disclosed a significantly higher prevalence of polyparasitism among the Orang Asli children (75.8 \%) compared to Malays (58.1\%) in Terengganu. The only study on the polyparasitism among Orang Asli children was conducted in Pahang state and reported that $71.4 \%$ of the children studied had polyparasitism [25]. Likewise, previous studies among the Orang Asli indicated that the majority of infected children were hosted two or more parasite species, with $T$. trichiura and A. lumbricoides representing the common mixed infection $[19,20,22,52]$. A similar situation was reported in different aboriginal communities in other countries [54, 60, 61].

The present study investigated the risk factors associated with intestinal polyparasitism among the studied children and revealed different scenarios in each population. In agreement with our findings, recent studies among the
Orang Asli communities reported a significantly higher prevalence of STH [20, 22], Giardia [24], Entamoeba spp. [41] and Blastocystis sp. [32, 34] infections among individuals who used unsafe sources for drinking water. Orang Asli prefer to live close to water streams and use water from these streams for most of their daily activities, including swimming, cooking, drinking, bathing and washing. Moreover, rivers are also their preferred sites for defecation, especially for children [25, 62]. This practice of indiscriminate defecation near the streams, around the houses, playgrounds and roadsides by the residents increases the contamination of the environment, thereby increasing the occurrences of infection and re-infection with IPIs. Moreover, the contamination of rivers with intestinal parasites was proven by previous reports conducted in Malaysia [63]. In Malaysia, the government has made intensive efforts to improve the quality of life of the indigenous people 
throughout the country, with their main strategy being to reallocate those living in remote areas to new settlements at the periphery of towns. However, the adherence of the Orang Asli people in Peninsular Malaysia to their jungle habitats has constrained these efforts. As an alternative, hundreds of houses were built or restored for the Orang Asli people in their remote areas [64]. Unfortunately, we observed that the toilets were used as storage rooms due to cultural beliefs that toilets should not be located inside the house and the lack of knowledge about the impact of sanitation.

Interestingly, the present study identified the presence of domestic animals in households as a significant risk factor of polyparasitism among both communities, Orang Asli and Malay. Previous studies in Malaysia reported a significant association between the presence of domestic animals and STH [20], Giardia [24], Entamoeba spp. [41] and Blastocystis sp. [65] infections. We found that domestic animals at the studied communities usually do not undergo deworming and therefore they are possible carriers of many parasites. The role of stray and domestic animals as reservoirs for zoonotic diseases has been known as a significant health problem worldwide [66, 67]. In the same vein, recent studies in rural and urban areas of different states of Malaysia revealed an extraordinary high level of soil contamination with STH eggs and highlighted the involvement of stray and domestic cats and dogs as sources of contamination $[68,69]$. Besides, a wide range of animal parasites such as Ancylostoma ceylanicum, Ancylostoma caninum, Toxocara spp., Dipylidium caninum, Spirometra spp., Entamoeba spp., G. duodenalis, Cryptosporidium spp., Balantidium coli and Isospora spp. were recovered in soil samples as well as dogs and cats faecal samples [68-71]. Similar findings have been reported in many previous reports from different developed and developing countries [72-76].

Eggs and larvae of STH, as well as cysts and oocysts of protozoans, can remain viable and infective in the environment for a very long period of time; hence, involvement of human and animals in a mechanical transmission of intestinal parasites can also be postulated. Infective stages present in the soil could easily get picked-up by the fur of animals (cats and dogs) and then not washing hands after handling or playing with these animals could facilitate the spread of the infections. Similarly, not wearing shoes when outside the house may result in skin penetration by hookworm larvae or contribute to the contamination of houses with eggs/ cysts/oocyst of other parasites and this was also identified by the present study as a significant predictor of polyparasitism among the Orang Asli children. This is in agreement with a previous report on polyparasitism among these children in Pahang state and other studies on STH and Giardia in Peninsular Malaysia [20, 24, 25].
In addition, Malay children of working mothers had a significantly higher prevalence of polyparasitism compared to their peers and this is in agreement with previous studies in Thailand [77], India [78] and Mexico [79]. The absence of mothers during the daytime causes the loss of many child healthcare and hygiene activities provided by the mothers and creates more opportunities for young children to get exposed and infected as they play outdoors. Similarly, we found that the Orang Asli children born to non-educated mothers had a significantly higher prevalence of polyparasitism compared to those of educated mothers and this is consistent with recent studies among Orang Asli in Malaysia [23, 25] and other countries [80-82]. Non-educated mothers would probably have less health-related knowledge and concern attitude, thus give less health guidance to their children.

Our findings also revealed that not washing vegetables prior to consumption was a significant risk factor of polyparasitism among the Orang Asli children. Vegetables could be the medium of transmission in cases where the surface carries parasite infective stages, especially when the vegetables have been in contact with the contaminated ground or due to contamination at the source by fertilisation with night soil. This finding is consistent with previous studies in Orang Asli communities [23$25]$ and other countries [83, 84]. A high level of parasitic contamination of raw vegetables was reported in Iran [85], Egypt [86], Saudi Arabia [87] and Zanzibar [88].

With regards to the respondents' KAP about IPIs, the present study showed distinct situations in both communities, with almost all the Malays having had heard about IPIs and having prior knowledge about IPIs signs and symptoms, ways of transmission and prevention. In contrast, although $75 \%$ of the Orang Asli respondents had heard about IPIs, only 75.6, 52.6 and $64.1 \%$ of them had knowledge on IPIs signs and symptoms, ways of transmission, and prevention, respectively. A similar level of knowledge was reported in Malaysia and abroad [22, 89].

Orang Asli settlements in Terengganu are located close to the Malay villages; that said, the environment's soil enrichment is not a determining factor for the parasite thriving, but the human factor is. The better knowledge and attitude among the Malays translated into significantly higher levels of hygienic practices among this population compared to Orang Asli. Hence, we believe that the high level of awareness pertaining to the IPIs is the essential factor that explains the distinct IPIs situation in both populations. At the same time, we cannot ignore the critical role of proper sanitation that helps break helminth transmission cycles and is considered a key component in any intestinal parasite control programme. It was concluded that awareness by itself might be not enough to protect these people from infection as the lack of access to safe drinking water and adequate sanitation are the driving 
forces behind the risk behaviour of individual community members [90]. Likewise, chemotherapy for the treatment of IPIs in highly endemic areas does not ensure protection against infection and has not had long-lasting success. For instance, previous studies from Malaysia and other countries have reported rapid reinfection of different IPIs including STH, schistosomiasis and protozoan infections. Within 6 months of complete deworming, the prevalence rate and intensity of infection were shown to return to the pre-treatment levels $[62,91]$. Overall, Orang Asli communities in rural Peninsular Malaysia have almost similar socioeconomic, environmental and health profiles. This is also applicable to rural Malay communities. Thus, we may speculate that the findings can be generalised to other rural Orang Asli and Malay children in other states. However, further studies are required to confirm this hypothesis.

\section{Limitations of the study}

Some limitations should be borne in mind when interpreting the findings of the present study. First, a cross-sectional design was used to gather results of the study and this limits our ability to confirm the causal relationship between IPIs and the identified risk factors. Secondly, this study had to rely on a single faecal sample instead of the ideal three consecutive samples because of the limitation of resources and the cultural belief of the Orang Asli against giving their faecal samples. Thus, the prevalence rate of IPIs is likely to be underestimated due to the temporal variation in egg excretion and cyst/oocysts shedding over hours and days [92]. Moreover, we used a single Kato-Katz smear instead of the multiple Kato-Katz smear examination that is reported to enhance the sensitivity of helminth diagnosis [93]. However, we used seven different methods to examine the faecal samples and this could help to overcome this limitation. Thirdly, the diagnostic techniques used in our study may have a low sensitivity for the detection of certain parasite species (eg Strongyloides stercoralis). This could also be due to the storage of faecal samples in cold temperature $\left(4-6{ }^{\circ} \mathrm{C}\right)$, which was found to interfere with the parasitological diagnosis of strongyloidiasis [94].

\section{Conclusions}

The findings of the present study show that IPIs are highly prevalent and are major public health concerns among rural communities in Terengganu state, with $68.5 \%(113 / 165)$ of the Orang Asli children having polyparasitism compared to $14.3 \%(25 / 175)$ of their Malay peers who reside the same areas. The presence of domestic animals was identified as a significant risk factor of polyparasitism in both populations, suggesting the potential role of animals in the epidemiological cycle of IPIs in these communities. Moreover, our findings clearly demonstrated a bigger web of causation of polyparasitism (including a subset of unhygienic practices, lack of access to safe drinking water and mothers' low education) among the Orang Asli communities than among the Malays.

In addition, all Malay participants had high levels of knowledge and attitude about IPIs compared to poor levels among their Orang Asli peers. Hence, there is a great need to implement an innovative and integrated control programme to reduce the prevalence of these infections significantly and to save these children from the possible negative impacts of IPIs as a part of the efforts to improve the quality of life of rural population. A proper health education regarding good personal hygiene practices, providing proper and adequate sanitation and safe water supply should be considered in the control programme targeting the Orang Asli population.

\section{Abbreviations}

$E P G$, eggs per gram of stool; IPIs, Intestinal parasitic infections:

KAP, knowledge, attitude and practices; STH, soil-transmitted helminths

\section{Acknowledgements}

The authors would like to acknowledge the Department of Orang Asli Development (JAKOA), Ministry of Rural and Regional Development, Kuala Lumpur, Malaysia for their generous support during this study. Thanks also are indebted to the parents and their children for their participation in this study. The authors are also very thankful to Mr. Abdulaziz Ali Alkazhi from University of Malaya for his fruitful help during field work.

\section{Funding}

This study was funded by the University of Malaya High Impact Research Grant UM-MOHE (UM.C/625/1/HIR/MOHE/MED/16) from the Ministry of Higher Education Malaysia, and also by the University of Malaya Research Grants; RG510-13HTM and RG331-15AFR. The funding bodies have no role in the study and publication process.

\section{Availability of data and material}

The datasets supporting the conclusions of this article are included within the article. Raw data are available from the authors upon request.

\section{Authors' contributions}

HMA, II and YLL designed and supervised the study. FNE, NAN and WMA conducted the sampling and field survey. HMA analysed the data. HMA, FNE and II wrote the paper. AMA, NAN, WMA, HS, SD, MAA, MHA and LRS were involved in the laboratory examination of samples. JS, NM and TSA revised the manuscript. All authors approved the final version of the manuscript.

\section{Competing interests}

The authors declare that they have no competing interests.

\section{Consent for publication}

Not applicable.

\section{Ethics approval and consent to participate}

The study was approved by the Medical Ethics Committee of the University of Malaya Medical Centre, Kuala Lumpur (Reference Number: 638.36). All participants gave a written signed or thumb-printed consent to take part in the study.

\section{Author details}

${ }^{1}$ Department of Parasitology, Faculty of Medicine, University of Malaya, 50603 Kuala Lumpur, Malaysia. ${ }^{2}$ Endemic and Tropical Diseases Unit, Medical Research Center, Jazan University, Jazan, Kingdom of Saudi Arabia.

${ }^{3}$ Department of Parasitology, Faculty of Medicine and Health Sciences, Sana'a University, Sana'a, Yemen. ${ }^{4}$ Integrative Pharmacogenomics Institute, Universiti Teknologi MARA, Puncak Alam Campus, 42300 Selangor, Malaysia.

${ }^{5}$ Department of Medical Laboratory Technology, Faculty of Health Sciences, Universiti Teknologi MARA, Puncak Alam Campus, 42300 Selangor, Malaysia. 
${ }^{6}$ Department of Parasitology and Medical Entomology, Universiti Kebangsaan Malaysia Medical Centre, Jalan Yaacob Latif, 56000 Kuala Lumpur, Malaysia. ${ }^{7}$ Centre for Research and Innovation, Taylor's University, Subang Jaya, 47500 Selangor, Malaysia.

\section{Received: 21 April 2016 Accepted: 1 July 2016} Published online: 16 July 2016

\section{References}

1. Hotez PJ, Alvarado M, Basáñez M-G, Bolliger I, Bourne R, Boussinesq M, et al. The global burden of disease study 2010: interpretation and implications for the neglected tropical diseases. PLoS Negl Trop Dis. 2014;8(7):e2865.

2. Pullan RL, Smith JL, Jasrasaria R, Brooker SJ. Global numbers of infection and disease burden of soil transmitted helminth infections in 2010. Parasit Vectors. 2014;7:37

3. Alum A, Rubino JR, ljaz MK. The global war against intestinal parasitesshould we use a holistic approach? Int J Infect Dis. 2010;14(9):e732-738.

4. Farrar J, Hotez P, Junghanss T, Kang G, Lalloo D, White N, editors. Manson's tropical diseases. 23rd ed. Edinburgh: Saunders Elsevier; 2014.

5. Hotez PJ, Fenwick A, Savioli L, Molyneux DH. Rescuing the bottom billion through control of neglected tropical diseases. Lancet. 2009;373(9674):1570-5.

6. Campbell SJ, Savage GB, Gray DJ, Atkinson JA, Soares Magalhães RJ, Nery SV, et al. Water, sanitation, and hygiene (WASH): A critical component for sustainable soil-transmitted helminth and schistosomiasis control. PLoS Negl Trop Dis. 2014;8(4):e2651.

7. Murray CJ, Barber RM, Foreman KJ, Abbasoglu Ozgoren A, Abd-Allah F, Abera SF, et al. Global, regional, and national disability-adjusted life years (DALYs) for 306 diseases and injuries and healthy life expectancy (HALE) for 188 countries, 1990-2013: quantifying the epidemiological transition. Lancet. 2015:386(10009):2145-91.

8. Nokes C, Bundy D. Does helminth infection affect mental processing and educational achievement? Parasitol Today. 1994;10:14-8.

9. Stoltzfus RJ, Chwaya HM, Montresor A, Albonico M, Savioli L, Tielsch JM. Malaria, hookworms and recent fever are related to anaemia and iron status indicators in 0- to 5-y old Zanzibari children and these relationships change with age. J Nutr. 2000;130:1724-33.

10. Shang YU, Tang LH, Zhou SS, Chen YD, Lin SX. Stunting and soil-transmitted helminth infections among school age pupils in rural areas of southern China. Parasit Vectors. 2010:3:97.

11. Al-Mekhlafi MH, Azlin M, Aini UN, Shaik A, Sa'iah A, Norhayati M. Prevalence and predictors of low serum retinol and hypoalbuminaemia among children in rural Peninsular Malaysia. Trans R Soc Trop Med Hyg. 2007;101(12):1233-40.

12. Ahmed A, Al-Mekhlafi H, Azam M, Ithoi I, Al-Adhroey A, Abdulsalam A, Surin J. Soil-transmitted helminthiasis: a critical but neglected factor influencing school participation of aboriginal children in rural Malaysia. Parasitol. 2012;139:802-8.

13. Al-Mekhlafi HM, Al-Maktari MT, Jani R, Ahmed A, Anuar TS, Moktar N, et al. Burden of Giardia duodenalis infection and its adverse effects on growth of school children in rural Malaysia. PLoS Negl Trop Dis. 2013:7(10):e2516.

14. Nokes C, Grantham-McGregor SM, Sawyer AW, Cooper ES, Robinson BA, Bundy DAP. Moderate-to-heavy infections with Trichuris trichiura affect cognitive function in Jamaican school children. Parasitol. 1992;104:539-47.

15. Gibson AK, Raverty S, Lambourn DM, Huggins J, Magargal SL, Grigg ME. Polyparasitism is associated with increased disease severity in Toxoplasma gondii-infected marine sentinel species. PLoS Negl Trop Dis. 2011;5(5):e1142.

16. Supali T, Verweij JJ, Wiria AE, Djuardi Y, Hamid F, Kaisar MM, et al. Polyparasitism and its impact on the immune system. Int J Parasitol. 2010; 40(10):1171-6.

17. Bleakley H. Disease and development: evidence from hookworm eradication in the American South. Quart J Econom. 2007;122:73-117.

18. Norhayati M, Zainudin B, Mohammod C, Oothuman P, Azizi O, Fatmah MS The prevalence of Trichuris, Ascaris and hookworm infection in Orang Asli children. Southeast Asian J Trop Med Public Health. 1997;28:161-8.

19. Al-Mekhlafi MS, Atiya AS, Lim YA, Mahdy AK, Ariffin WA, Abdullah HC, et al. An unceasing problem: soil-transmitted helminthiases in rural Malaysian communities. Southeast Asian J Trop Med Public Health. 2007;38:998-1007.

20. Ahmed A, Al-Mekhlafi HM, Choy SH, Ithoi I, Al-Adhroey AH, Abdulsalam AM, et al. The burden of moderate-to-heavy soil-transmitted helminth infections among rural Malaysian aborigines: an urgent need for an integrated control program. Parasit Vectors. 2011;4:242.

21. Al-Delaimy AK, Al-Mekhlafi HM, Lim YA, Nasr NA, Sady H, Atroosh WM, et al. Developing and evaluating health education learning package (HELP) to control soil-transmitted helminth infections among Orang Asli children in Malaysia. Parasit Vectors. 2014:7:416.

22. Nasr NA, Al-Mekhlafi HM, Ahmed A, Roslan MA, Bulgiba A. Towards an effective control program of soil-transmitted helminth infections among Orang Asli in rural Malaysia. Part 1: Prevalence and associated key factors. Parasit Vectors. 2013:6:27.

23. Anuar TS, Salleh FM, Moktar N. Soil-transmitted helminth infections and associated risk factors in three Orang Asli tribes in Peninsular Malaysia. Sci Rep. 2014;4:4101.

24. Choy SH, Al-Mekhlafi HM, Mahdy MA, Nasr NN, Sulaiman M, Lim YA, et al. Prevalence and associated risk factors of Giardia infection among indigenous communities in rural Malaysia. Sci Rep. 2014;4:6909.

25. Al-Delaimy AK, Al-Mekhlafi HM, Nasr NA, Sady H, Atroosh WM, Nashiry M, et al. Epidemiology of intestinal polyparasitism among Orang Asli school children in rural Malaysia. PLoS Negl Trop Dis. 2014;8(8):e3074.

26. Department of Statistics Malaysia. Profile of Orang Asli in Peninsular Malaysia, Kuala Lumpur (http://www.statistics.gov.my). Accessed 23 Jan 2016.

27. Lwanga SK, Lemeshow S. Sample size determination in health studies: a practical manual. Geneva: World Health Organization; 1991.

28. Cheesbrough M. District laboratory practice in tropical countries: Part 1. 2nd ed. London: Cambridge University Press; 2005.

29. World Health Organization. Helminth control in school-age children: a guide for managers of control programmes. Geneva: World Health Organization; 2006.

30. Jozefzoon LM, Oostburg BF. Detection of hookworm and hookworm-like larvae in human fecocultures in Suriname. Am J Trop Med Hyg. 1994;51:501-5.

31. World Health Organization. Training manual on diagnosis of intestinal parasites. Geneva: World Health Organization; 1998.

32. Anuar TS, Ghani MK, Azreen SN, Salleh FM, Moktar N. Blastocystis infection in Malaysia: evidence of waterborne and human-to-human transmissions among the Proto-Malay, Negrito and Senoi tribes of Orang Asli. Parasit Vectors. 2013:6:40

33. Henriksen SA, Pohlenz JF. Staining of cryptosporidia by a modified Ziehl-Neelsen technique. Acta Vet Scand. 1981;22:594-6.

34. Abdulsalam AM, Ithoi I, Al-Mekhlafi HM, Ahmed A, Surin J, Mak JW. Drinking water is a significant predictor of Blastocystis infection among rural Malaysian primary schoolchildren. Parasitology. 2012;139(8):1014-20.

35. Tan KS. New insights on classification, identification, and clinical relevance of Blastocystis spp. Clin Microbiol Rev. 2008;21:639-65.

36. Bendel RB, Afifi AA. Comparison of stopping rules in forward "stepwise" regression. J Am Stat Assoc. 1977;72:46-53.

37. Rabinowitz VC, Valian V. Sex, sex differences, and social behavior. Ann N Y Acad Sci. 2000;907:196-207.

38. World Health Organization. Health statistics and information systems. Geneva: World Health Organization; 2015. (http://www.who.int/healthinfo/ global_burden_disease/metrics_paf/en/). Accessed: 1 February 2016.

39. Lee SC, Ngui R, Tan TK, Muhammad Aidil R, Lim YAL. Neglected tropical diseases among two indigenous subtribes in Peninsular Malaysia: highlighting differences and co-infection of helminthiasis and sarcocystosis. PLoS One. 2014;9(9):e107980.

40. Noor Azian MY, San YM, Gan CC, Yusri MY, Nurulsyamzawaty Y, Zuhaizam $\mathrm{AH}$, et al. Prevalence of intestinal protozoa in an aborigine community in Pahang, Malaysia. Trop Biomed. 2007:24:55-62.

41. Shahrul Anuar T, Al-Mekhlafi HM, Abdul Ghani MK, Osman E, Mohd Yasin A, Nordin A, et al. Prevalence and risk factors associated with Entamoeba histolytica/dispar/moshkovskii infection among three Orang Asli ethnic groups in Malaysia. PLoS One. 2012;7:e48165.

42. Coyle CM, Varughese J, Weiss LM, Tanowitz HB. Blastocystis: to treat or not to treat. Clin Infect Dis. 2012;54:105-10.

43. Clark CG, van der Giezen M, Alfellani MA, Stensvold CR. Recent developments in Blastocystis research. Adv Parasitol. 2013:82:1-32.

44. Roberts T, Stark D, Harkness J, Ellis J. Update on the pathogenic potential and treatment options for Blastocystis sp. Gut Pathog. 2014;6:17.

45. Chandramathi S, Suresh K, Sivanandam S, Kuppusamy UR. Stress exacerbates infectivity and pathogenicity of Blastocystis hominis: in vitro and in vivo evidences. PLoS One. 2014;9(5):e94567.

46. Kumarasamy V, Kuppusamy UR, Samudi C, Kumar S. Blastocystis sp. subtype 3 triggers higher proliferation of human colorectal cancer cells, HCT116. Parasitol Res. 2013;112(10):3551-5.

47. Rajamanikam A, Govind SK. Amoebic forms of Blastocystis spp. - evidence for a pathogenic role. Parasit Vectors. 2013;6(1):295. 
48. Kumarasamy V, Roslani AC, Rani KU, Kumar GS. Advantage of using colonic washouts for Blastocystis detection in colorectal cancer patients. Parasit Vectors. 2014;7:162.

49. Sinniah B, Rajeswari B. Blastocystis hominis infection, a cause of human diarrhoea. Southeast Asian J Trop Med Public Health. 1994;25:490-3.

50. Rajeswari B, Sinniah B, Hussein H. Socio-economic factors associated with intestinal parasites among children living in Gombak, Malaysia. Asia Pac J Public Health. 1994;7:21.

51. Jamaiah I, Rohela M. Prevalence of intestinal parasites among members of the public in Kuala Lumpur, Malaysia. Southeast Asian J Trop Med Public Health. 2005:36:68-71.

52. Sinniah B, Hassan AKR, Sabaridah I, Soe MM, Ibrahim Z, Ali O. Prevalence of intestinal parasitic infections among communities living in different habitats and its comparison with one hundred and one studies conducted over the past 42 years (1970 to 2013) in Malaysia. Trop Biomed. 2014;31(2):190-206.

53. Belizario Jr VY, Totañes Fl, de Leon WU, Lumampao YF, Ciro RN. Soiltransmitted helminth and other intestinal parasitic infections among school children in indigenous people communities in Davao del Norte, Philippines. Acta Trop. 2011;120(Suppl):12-8.

54. Hotez PJ. Aboriginal populations and their neglected tropical diseases. PLoS Negl Trop Dis. 2014:8(1):e2286.

55. Auer C. Health status of children living in a squatter area of Manila, Philippines, with particular emphasis on intestinal parasitoses. Southeast Asian J Trop Med Public Health. 1990;21(2):289-300.

56. Raso G, Luginbühl A, Adjoua CA, Tian-Bi NT, Silué KD, Matthys B, et al. Multiple parasite infections and their relationship to self-reported morbidity in a community of rural Côte d'Ivoire. Int J Epidemiol. 2004;33:1092-102.

57. Brooker S, Miguel EA, Moulin S, Luoba Al, Bundy DAP, Kremer M. Epidemiology of single and multiple species of helminth infections among school children in Busia District, Kenya. East Afr Med J. 2000;77:157-61.

58. Mupfasoni D, Karibushi B, Koukounari A, Ruberanziza E, Kaberuka T, Kramer $\mathrm{MH}$, et al. Polyparasite helminth infections and their association to anaemia and undernutrition in northern Rwanda. PLoS Negl Trop Dis. 2009;3(9):e517.

59. Tchuem Tchuente LA, Behnke JM, Gilbert FS, Southgate VR, Vercruysse J. Polyparasitism with Schistosoma haematobium and soil-transmitted helminth infections among school children in Loum, Cameroon. Trop Med Int Health. 2003;8:975-86.

60. Thompson RC, Reynoldson JA, Garrow SC, McCarthy JS, Behnke JM. Towards the eradication of hookworm in an isolated Australian community. Lancet. 2001;357:770-1.

61. Taranto NJ, Cajal SP, De Marzi MC, Fernández MM, Frank FM, Brú AM, et al. Clinical status and parasitic infection in a Wichí Aboriginal community in Salta, Argentina. Trans R Soc Trop Med Hyg. 2003;97(5):554-8.

62. Al-Mekhlafi HMS, Surin J, Atiya AS, Ariffin WAW, Mahdy AKM, Abdullah HC. Pattern and predictors of soil-transmitted helminth re-infection among aboriginal school children in rural peninsular Malaysia. Acta Trop. 2008;107:200-4.

63. Azman J, Init I, Wan Yusoff WS. Occurrence of Giardia and Cryptosporidium (oo)cysts in the river water of two recreational areas in Selangor, Malaysia. Trop Biomed. 2009;26(3):289-302.

64. Ministry of Rural and Regional Development. Improving rural basic infrastructure. Annual report. Putrajaya: Ministry of Rural and Regional Development; 2010.

65. Salim HR, Kumar GS, Vellayan S, Mak JW, Anuar AK, Init I, et al. Blastocystis in animal handlers. Parasitol Res. 1999;85:1032-3.

66. Schantz PM. Of worms, dogs, and human hosts: continuing challenges for veterinarians in prevention of human disease. J Am Vet Med Assoc. 1994; 204:1023-8.

67. Robertson ID, Imwin PJ, Lymbery AJ, Thompson RC. The role of companion animals in the emergence of parasitic zoonoses. Int J Parasitol. 2000;30(12-13):1369-77.

68. Mohd Zain SN, Rahman R, Lewis JW. Stray animal and human defecation as sources of soil-transmitted helminth eggs in playgrounds of Peninsular Malaysia. J Helminthol. 2015;89(6):740-7.

69. Tun S, Ithoi I, Mahmud R, Samsudin NI, Kek Heng C, Ling LY. Detection of helminth eggs and identification of hookworm species in stray cats, dogs and soil from Klang Valley, Malaysia. PLoS One. 2015;10(12):e0142231.

70. Ngui R, Lee SC, Yap NJ, Tan TK, Aidil RM, Chua KH, et al. Gastrointestinal parasites in rural dogs and cats in Selangor and Pahang states in Peninsular Malaysia. Acta Parasitol. 2014;59(4):737-44.

71. Ngui R, Lim YAL, Traub R, Mahmud R, Mistam MS. Epidemiological and genetic data supporting the transmission of Ancylostoma ceylanicum among human and domestic animals. PLoS Negl Trop Dis. 2012;6(2):e1522.
72. Fok E, Szatmári V, Busák K, Rozgonyi F. Prevalence of intestinal parasites in dogs in some urban and rural areas of Hungary. Vet Q. 2001;23(2):96-8.

73. Traub RJ, Robertson ID, Irwin P, Mencke N, Thompson RC. The role of dogs in transmission of gastrointestinal parasites in a remote tea-growing community in northeastern India. Am J Trop Med Hyg. 2002;67:539-45

74. Traub RJ, Inpankaew T, Sutthikornchai C, Sukthana Y, Thompson RCA. PCR-based coprodiagnostic tools reveal dogs as reservoirs of zoonotic ancylostomiasis caused by Ancylostoma ceylanicum in temple communities in Bangkok. Vet Parasit. 2008;155:67-73.

75. Traversa D, Frangipane Di Regalbono A, di Cesare A, La Torre F, Drake J, Pietrobelli M. Environmental contamination by canine geohelminths. Parasit Vectors. 2014;7:67

76. Soriano SV, Pierangeli NB, Roccia I, Bergagna HF, Lazzarini LE, Celescinco A, et al. A wide diversity of zoonotic intestinal parasites infects urban and rural dogs in Neuquén, Patagonia, Argentina. Vet Parasitol. 2010;167(1):81-5.

77. Tomono N, Anantaphruti MT, Jongsuksuntigul P, Thongthien P, Leerapan $\mathrm{P}$, Silapharatsamee $Y$, et al. Risk factors of helminthiases among schoolchildren in southern Thailand. Southeast Asian J Trop Med Public Health. 2003;34:264-8.

78. Naish S, McCarthy J, Williams G. Prevalence, intensity and risk factors for soil-transmitted helminth infection in a South Indian fishing village. Acta Trop. 2004;91:177-87.

79. Quihui L, Valencia ME, Crompton DW, Phillips S, Hagan P, Morales G, et al. Role of the employment status and education of mothers in the prevalence of intestinal parasitic infections in Mexican rural schoolchildren. BMC Public Health. 2006;6:225

80. Okyay P, Ertug S, Gultekin B, Onen O, Beser E. Intestinal parasites prevalence and related factors in school children, a western city sample-Turkey. BMC Public Health. 2006;4:64.

81. Nematian J, Nematian E, Gholamrezanezhad A, Asgari AA. Prevalence of intestinal parasitic infections and their relation with socio-economic factors and hygienic habits in Tehran primary school students. Acta Trop. 2004; 92(3):179-86.

82. Al-Mohammed HI, Amin TT, Aboulmagd E, Hablus HR, Zaza BO. Prevalence of intestinal parasitic infections and its relationship with sociodemographics and hygienic habits among male primary schoolchildren in Al-Ahsa, Saudi Arabia. Asian Pac J Trop Med. 2010;3(11):906-12.

83. Ulukanligil M, Seyrek A, Aslan G, Ozbilge H, Atay S. Environmental pollution with soil-transmitted helminths in Sanliurfa, Turkey. Mem Inst Oswaldo Cruz. 2001;96(7):903-9.

84. Damen JG, Banwat EB, Egah DZ, Allanana JA. Parasitic contamination of vegetables in Jos, Nigeria. Ann Afr Med. 2007;6(3):115-8.

85. Shahnazi M, Jafari-Sabet M. Prevalence of parasitic contamination of raw vegetables in villages of Qazvin Province, Iran. Foodborne Pathog Dis. 2010;7(9):1025-30

86. Eraky MA, Rashed SM, Nasr M-S, El-Hamshary AM, Salah El-Ghannam A Parasitic contamination of commonly consumed fresh leafy vegetables in Benha, Egypt. J Parasitol Res. 2014;2014:613960.

87. Al-Binali AM, Bello CS, El-Shewy K, Abdulla SE. The prevalence of parasites in commonly used leafy vegetables in South Western, Saudi Arabia. Saudi Med J. 2006;27(5):613-6.

88. Knopp S, Mohammed KA, Stothard JR, Khamis IS, Rollinson D, Marti H, et al. Patterns and risk factors of helminthiasis and anemia in a rural and a periurban community in Zanzibar, in the context of helminth control programs. PLoS Negl Trop Dis. 2010;4(5):e681.

89. Midzi N, Mtapuri-Zinyowera S, Mapingure MP, Paul NH, Sangweme D, Herema G, et al. Knowledge, attitudes and practices of grade three primary schoolchildren in relation to schistosomiasis, soil-transmitted helminthiasis and malaria in Zimbabwe. BMC Infect Dis. 2011;11:169.

90. Grimes JE, Croll D, Harrison WE, Utzinger J, Freeman MC, Templeton MR. The roles of water, sanitation and hygiene in reducing schistosomiasis: a review. Parasit Vectors. 2015:8:156.

91. Senghor B, Diaw OT, Doucoure S, Sylla SN, Seye M, Talla I, et al. Efficacy of praziquantel against urinary schistosomiasis and reinfection in Senegalese school children where there is a single well-defined transmission period. Parasit Vectors. 2015;8:362.

92. Hall A. Quantitative variability of nematode egg counts in faeces: a study among rural Kenyans. Trans R Soc Trop Med Hyg. 1981;75:682-7. 
93. Sayasone S, Utzinger J, Akkhavong K, Odermatt P. Repeated stool sampling and use of multiple techniques enhance the sensitivity of helminth diagnosis: a cross-sectional survey in southern Lao People's Democratic Republic. Acta Trop. 2015;141:315-21.

94. Montes M, Sawhney C, Barros N. Strongyloides stercoralis: there but not seen. Curr Opin Infect Dis. 2010;23:500-4.

Submit your next manuscript to BioMed Central and we will help you at every step:

- We accept pre-submission inquiries

- Our selector tool helps you to find the most relevant journal

- We provide round the clock customer support

- Convenient online submission

- Thorough peer review

- Inclusion in PubMed and all major indexing services

- Maximum visibility for your research

Submit your manuscript at www.biomedcentral.com/submit 